\title{
What Would the Screen-and-Treat Strategy for Helicobacter pylori Mean in Terms of Antibiotic Consumption?
}

\author{
Mārcis Leja ${ }^{1,2,3,4}$ (D) Uga Dumpis ${ }^{2,5}$ (D)
}

Received: 29 May 2019 / Accepted: 3 October 2019 / Published online: 28 October 2019

(c) Springer Science+Business Media, LLC, part of Springer Nature 2019

\begin{abstract}
Several guidelines recommend the screen-and-treat strategy, i.e. active search for the presence of Helicobacter pylori infection and its eradication to prevent the possibility of gastric cancer. It is thought that a relatively short duration antibiotic regimen given once in a lifetime would not significantly increase overall antibiotic consumption. However, this would mean offering antibiotic treatment to the majority of the population in countries with the biggest burden of gastric cancer who would, therefore, have the greatest benefit from such a strategy. So far, no country has implemented an eradication strategy. With an example based on the current situation in Latvia, we have estimated the increase in antibiotic consumption if the screen-and-treat strategy was applied. Depending on the scenario that might be chosen, clarithromycin consumption would increase up to sixfold, and amoxicillin consumption would double if the recommendations of the current guideline in the local circumstances was applied. It appears that an increase in commonly used antibiotic consumption cannot be justified from the viewpoint of antibiotic stewardship policies. Solutions to this problem could be the use of antibiotics that are not required for treating life-threatening diseases or more narrow selection of the target group, e.g. young people before family planning to avoid transmission to offspring. Additional costs related to the increase in resistome should be considered for future cost-effectiveness modelling of the screen-and-treat strategy.
\end{abstract}

Keywords Screen-and-treat $\cdot$ H. pylori $\cdot$ Gastric cancer $\cdot$ Prevention $\cdot$ Resistome $\cdot$ Cost-effectiveness $\cdot$ Antibiotic stewardship

\section{Introduction}

Although declining in incidence, gastric cancer will remain an important healthcare issue for the foreseeable future due to aging and the increase in global population. The group of experts gathered by the International Agency for Research on Cancer (IARC) has suggested implementation of gastric cancer prevention by Helicobacter pylori (H. pylori) eradication in well-controlled research settings (ML was part of the working group) [1].

Mārcis Leja

marcis.leja@lu.lv

1 Institute of Clinical and Preventive Medicine, University of Latvia, 19 Raiņa boulv., Riga LV1586, Latvia

2 Faculty of Medicine, University of Latvia, Riga, Latvia

3 Riga East University Hospital, Riga, Latvia

4 Digestive Diseases Centre GASTRO, Riga, Latvia

5 Paul Stradins' Clinical University Hospital, Riga, Latvia
The annual total number of new cases accounts for $\sim$ one million, responsible for $>8 \%$ of global cancer-related deaths each year [2]. This number is estimated to remain stable for at least the next 30 years if no prevention measures are implemented [3].

Infection with $H$. pylori is the key risk factor for this type of cancer, responsible for $\sim 90 \%$ of the distal (non-cardia) cancer cases $[4,5]$.

Several prevention strategies, including primary and secondary prevention are suggested to decrease the mortality caused by gastric cancer. Only about $1-2 \%$ of individuals infected with $H$. pylori are likely to develop gastric cancer in their lifetime [6,7]. Ideally, only the bacteria potentially leading to cancer or other diseases should be eradicated; however, risk stratification attempts based on H. pylori virulence factor identification or host susceptibility, e.g. by detecting the relevant polymorphisms of proinflammatory cytokines, have not led to a strategy that could be recommended for routine practice [8]. Vaccine 
development still does not provide encouraging results suggesting that it is close to a routine practice [9].

Eradication of $H$. pylori in adults hosting the infection appears to be the most effective prevention strategy. The only reliable approach to eliminate the infection is simultaneous use of at least two different antibiotics in combination with potent acid suppression using a proton pump inhibitor or a potassium-competitive acid blocker (PCAB) [10].

\section{A Screen-and-Treat Strategy}

A screen-and-treat strategy would mean active testing for presence of $\mathrm{H}$. pylori in the (mostly healthy) general population, and offering eradication to those testing positive [11]. It is expected that $H$. pylori eradication would reduce the risk of gastric cancer in the population for 34\% [11]. Such a strategy should comply with the principles of good governance and organization, and the benefits should be well-balanced against the risks that any potential intervention could create [12]. Several risks have been suggested for population-based H. pylori eradication; however, the possible adverse effects related to increased antibiotic consumption probably are the most significant. Resistant $H$. pylori strains are emerging due to high antibiotic consumption [13]. However, the most significant risks will probably be related to induction of resistance in other clinically relevant bacteria than $H$. pylori and increase the pool of resistant genes in the gut and upper respiratory system [14-16].

The currently recommended choice of antibiotics depends on the local resistance pattern of $H$. pylori, unless susceptibility-based individual therapy is prescribed [10, 11]. Clarithromycin and amoxicillin are the most widely prescribed antibiotics, frequently used in both low and high clarithromycin-resistant regions. According to the guidelines, the clarithromycin-containing regimen is the choice where $H$. pylori is clearly sensitive to clarithromycin (for individualized treatment) or if $H$. pylori resistance to clarithromycin does not exceed $15 \%$ in the reference population [11]. Although the resistance of $H$. pylori to clarithromycin correlates to the overall use of this antibiotic in a particular population, the choice of treatment solely depends on H. pylori resistance. Furthermore, no differences in the eradication regimen are currently recommended, depending on whether the treatment is given for a clinically evident disease, e.g. for complicated ulcer disease or MALT lymphoma from prevention strategies in population-based settings. The author viewpoint is that negative effects upon the gut microbiome would not be a significant concern in the case of treating patients with a clinically significant disease, yet should be considered in preventive interventions.

\section{Screen-and-Treat in Guidelines}

The European Maastricht V/Florence consensus (ML was part of the working group) recommended the screenand-treat strategy in communities at high risk of gastric cancer and consideration of this approach in communities with intermediate to low risk of gastric cancer [11]. Kyoto global consensus has for the first time categorized H. pylori gastritis as an infectious disease, irrespective of symptoms and complications [17], which has been reinforced by the Maastricht V [11] and Brazilian consensus [18]. All H. pylori infected subjects are recommended to undergo eradication therapy according to the Kyoto consensus unless there are competing considerations, such as comorbidities, re-infection rates in their communities, competing health priorities of society or financial issues [17].

The recent guidelines of ASEAN (Association Southeast Asian Nations) countries support eradication to prevent gastric cancer by considering this strategy as costeffective, depending on the disease burden in the relevant community [19]. A similar opinion was formed in the Second Asia-Pacific Consensus Guidelines for H. pylori infection a decade ago for communities with high incidence of gastric cancer [20].

At the same time, some of the guidelines and expert group recommendations are less enthusiastic regarding population-based eradication. The American College of Gastroenterology does not recommend active search of H. pylori in an asymptomatic population [21]. An expert group hosted by IARC has suggested the need for interventional strategies to decrease the burden of gastric cancer $[1,22]$; however, experts recommended that this be done by the means of well-designed clinical studies evaluating the feasibility, acceptance, costs, effectiveness and adverse consequences. A European expert group (ML was part of the working group) within the EU Joint Action in Cancer Control (CanCon) has been even more critical-they concluded that, as of today, there is no screening method that can be readily recommended for implementation in the EU Member States, although there seems to be a need for one [12]. This also included the screen-and-treat strategy for H. pylori.

There is common agreement $[8,11,17]$ that the optimal timing for eradicating $H$. pylori must come before the development of precancerous lesions, since a proportion of the subjects could be progressing to gastric cancer if eradicated at the stage that precancerous lesions (atrophy, intestinal metaplasia, dysplasia) become evident.

In Japan, currently eradication therapy is reimbursed for all the individuals with $H$. pylori infection and active gastritis (in addition to the ongoing screening activities for 
gastric cancer), which means that endoscopy is required to confirm the condition. Thereafter, significant increase in eradication therapies has occurred [23], yet this cannot be considered an organized screening strategy. In Korea, a high gastric cancer incidence country with a gastric cancer screening program [24], $H$. pylori management guidelines do not address the search for the presence of the bacteria in general population [25].

The country probably closest to the real implementation of screen-and-treat strategy in an organized way is Slovenia, where the professional society has issued guidelines for such a strategy [26]; it must be mentioned that this country has considerable experience in implementing other types of cancer screening in an organized manner, including screening for colorectal cancer.

\section{Duration of the Treatment}

Fourteen-day duration of eradication therapies, including for bismuth-containing therapies, is currently recommended by Maastricht V, unless shorter duration therapies (10 days) are proven effective locally [11]. Similarly, the Toronto consensus recommends a 14-day treatment [27].

It is noteworthy that the recommended duration of treatment has extended with the time to achieve higher effectiveness of these therapies. In 2005, the Maastricht III consensus considered 7 days as a valid duration for treatment [28]. Maastricht IV in 2010 extended treatment to 10-14 days giving a gain of $\sim 5 \%$ in the success rates [29].

\section{Compliance with the General Principles of Screening}

The general WHO principles for screening have been set more than half a century ago by Wilson and Jungner [30], and they are still used as of today although updated in the new genomic era [31]. Furthermore, principles of good screening organization and governance have been consistently emphasized by the expert groups [12]. The above principles include implementation of the program only when sufficient scientific evidence (with proven effects on the mortality as the end-point) is available and following thorough cost effectiveness analysis, precise definition of the target population as well as invitation strategy, piloting of a screening system, setting up a robust quality assurance system before the system is launched in full operation.

H. pylori infection is highly prevalent, affecting about half of the global population [32]; the prevalence of precancerous lesions in the general population is also considerable [33]. Therefore, population-based efforts such as the screen-and-treat strategy should follow the general rules of screening. It must be mentioned that the current $H$. pylori management guidelines so far are lacking this approach.

\section{Potential Impact of Standard H. pylori Eradication Therapy}

Adverse events related to $H$. pylori eradication therapy are common, but usually they are mild and of short-term duration; the most common symptoms are diarrhea, nausea and/or vomiting, epigastric pain, and altered taste [34]. A large systemic review performed in 2004 demonstrated adverse effects in $22 \%$ of the subjects receiving eradication therapy for peptic ulcer compared to $8 \%$ in patients on a proton pump inhibitor (PPI) or no treatment (RR 2.28; 95\% CI: 1.72 to 3.02 ) [34].

Treatment with oral and parenteral antibiotics results in a rapid and significant alteration of the intestinal microbiota. The most obvious outcome of disruption of normal gut microbiome is Clostridium difficile infection (CDI). CDI is a major threat to both outpatients and those hospitalized.

Although any antimicrobium can predispose a patient to CDI, the risk is especially great when using broad-spectrum antimicrobials, which disrupt normal enteric flora [35]. Prolonged treatment with antimicrobial agents is also associated with an increased risk of CDI by extending the time disruption of normal enteric flora [36].

Although not being a typical adverse event, a number of cases have been published on CDI after eradication therapy of $H$. pylori [37]. Awareness of the complication is particularly important when both duration and indications for $H$. pylori eradication therapy have been extended.

Significant perturbation of the gut microbiome might follow the use of antibiotics; however, in the majority of cases the gut microflora would be expected to return to its initial state within a few months $[38,39]$.

Resistome is defined as a collection of all antibiotic resistance genes and their precursors in both pathogenetic and non-pathogenic bacteria [40]. The gut microbiota is a large reservoir of antibiotic-resistance genes [41]; an average number of 21 such genes per sample has been reported [42].

Many earlier and more recent studies have suggested long-lasting persistence of resistant pharyngeal and/or gut bacteria following the use of traditional antibiotics used to eradicate $H$. pylori.

One-week treatment of healthy volunteers with macrolides (azithromycin or clarithromycin) has been associated to a significantly increased proportion of macrolide-resistant streptococci in the pharynx compared to a placebo-treated group; resistant streptococci were present for up to 180 days following treatment [16]. Similar data on macrolide-resistant streptococci persistence in the pharynx for more than 1 year in patients receiving clarithromycin-containing $H$. pylori eradication regimens have been reported by others [43].

Another study has addressed the presence of resistant Staphylococcus, Streptococcus, Enterococcus and 
Bacteroides spp. in samples from nostrils, throat and feces before, 2 weeks and 1 year following triple $H$. pylori eradication therapy (clarithromycin, metronidazole and omeprazole for 7 days) in a group with peptic ulcer disease, as well as a control group not receiving this treatment [44]. Resistant isolates, in particular of Staphylococci and Streptococci were higher after 1 year, but not in the control group. Another study based on the same patient data demonstrated that this treatment facilitated the selection of highly resistant enterococci present, even 3 years after treatment [45]. The same group has also addressed $\operatorname{erm}(\mathrm{B})$ gene levels (one of the mechanisms for macrolide resistance) both in throat and fecal samples. These levels increased dramatically by $3-5$ orders of magnitude immediately after antibiotic treatment. In a proportion of the subjects, $\operatorname{erm}(\mathrm{B})$ remained elevated 4 years after treatment [46]. However, the small sample of subjects in this study should be noted.

More recently, larger studies applying 16S rRNA gene and metagenomic sequencing have been reported by Yap et al. [15] who investigated stool samples in 17-year-old volunteers from Malaysia before $H$. pylori eradication, and at 6, 12, 18 months thereafter. Despite microbial diversity was similar pre- and post- $H$. pylori eradication with no significant differences in richness and evenness of bacterial species, changes in the bacterial communities at the phylum and genus levels were noted, e.g., the relative abundance of Bacterioidetes decreased and Firmicutes increased.

An important study primarily addressing metabolic effects of $H$. pylori eradication in general population in Taiwan was recently published [47]. Significant perturbation of gut microbiota in short-term was revealed, and it was significantly greater for concomitant and bismuth quadruple therapies than for a standard triple. Bismuth quadruple therapy, on the other hand, was not associated with an increase in resistance in E. coli. The authors also demonstrated that for other therapies the resistance rates of E. coli and K. pneumoniae to certain antibiotics were restored at week 8 and 1 year after therapy [47]. However, this study focussed only on gut microbiome and effect on resistance rates in Gram-negative bacteria. Widespread use of amoxicillin and clarithromycin causes concern about resistance rates in Gram-positive bacteria such as Str. pneumoniae and S. aureus [48, 49].

Current evolution of sequencing methods will provide significant evidence related to the potential perturbation of microbiota following antibiotic treatment, including $H$. pylori eradication. Several studies comparing the effect of different $H$. pylori eradication regimens on the gut microbiome or resistome are in progress in different countries, including Taiwan, Spain and Latvia. In most of them, the diversity of microbiota is addressed by means of $16 \mathrm{~S}$ rRNA gene sequencing, whereas others apply metagenome sequencing.

\section{Antimicrobial Stewardship Activities}

The use of antibiotics is the primary driver for the development of resistance and also leads to other adverse effects ranging from allergic reactions to CDI [50].

The term "antimicrobial stewardship" is encountered in a growing number and increasingly diverse range of contexts, from antimicrobial stewardship programmes in hospitals and the community [51], to veterinary antimicrobial stewardship [52], One Health antimicrobial stewardship [53] and the WHO global stewardship framework [54]. Because of the rapidly increasing use of the term without a sole clear definition, it has evolved differently in different settings, influenced by local interpretations [55].

In general, antimicrobial stewardship programs have a direct responsibility to ensure prudent antibiotic prescribing. Reducing antibiotic exposure should minimize the duration and extent of disruption of the microbiome, thereby reducing collateral damage and improving patient outcomes. Prolonged courses of antibiotics also increase the risk of colonization with multidrug resistant organisms. Therefore, the chain of transmission increases the risk of horizontally infecting more than one patient. Interrupting this chain is as important as preventing the development of resistance.

Data from developed nations suggest that $80 \%$ or more of antibiotic prescriptions are for outpatients [56]. Therefore, limiting their use of antibiotics is essential in reducing both resistance and adverse events.

Over the last 20 years, several developed countries introduced nationwide initiatives aimed at reduced antibiotic consumption, achieved a drop of $>30 \%$. In Sweden between 1992 and 2016, the number of prescriptions per 1000 inhabitants per year in outpatient care, including primary health care, decreased by $43 \%$ from 560 to 318 , whereas among children aged $0-4$ years it decreased by $73 \%$ from 1328 to 349 [57].

Between 2012 and 2017, a statistically significant decreasing trend in antibiotic use was also seen in Finland, Luxembourg and Norway [58].

In March 2015, the White House released the National Action Plan for Combating Antibiotic-Resistant Bacteria, which set a target of reducing inappropriate antibiotic use in the outpatient setting by $50 \%$ by 2020 [59].

In light of these trends, any suggestion for mass treatment of infections that would lead to an increase in antibiotic consumption will be carefully scrutinized by national authorities and experts.

Amoxicillin and clarithromycin, drugs of choice for treatment of $H$. pylori infections suggested by current guidelines, have wide application for the treatment of several community-acquired infections and account for large 
proportion of ambulatory antibiotic prescriptions in many countries. They are part of the suggested first or second line treatment regimens for community acquired pneumonia [60-63]. Amoxicillin or amoxicillin/clavulanate is often suggested as first-line treatment for otitis media, bacterial rhinosinusitis, dental infection and urinary tract infections. Macrolides are often recommended as replacement treatment for patients with penicillin allergy.

Use of azithromycin has been suggested for mass treatment for Chlamydia trachomatis eye infections in developing countries. This has already provoked significant concern on its potential adverse events, even though the prevalence of Chlamydia is significantly lower than $\mathrm{H}$. pylori. Monitoring of the resistance in multiple organisms has been suggested on this indication [64].

\section{Estimated Increase in Antibiotic Consumption in a Model of Latvia}

We conducted an exercise by estimating the expected increase in clarithromycin and amoxicillin consumption in Latvia if an $H$. pylori eradication program would be implemented. Latvia is a small country (population two million) in northern Europe with a relatively low consumption of antibiotics and relatively high incidence of gastric cancerthe incidence per 100,000 inhabitants in both genders is 12.9 (ASR, world population) [65].

We used data on the clarithromycin (J01FA09), amoxicillin (J01CR04), and amoxicillin beta-lactam combination (J01CR02) consumption in the country provided by the State Agency of Medicines and expressed in defined daily doses (DDD) per 1000 inhabitants in Latvia within the period 2014-2018. Mathematical projection for the next 3 years was made, and population distribution per relevant age groups from the official statistics was used. According to the guidelines [11], a 14-day eradication regimen with $2 \mathrm{~g}$ per day amoxicillin and $1 \mathrm{~g}$ per day clarithromycin was used in the estimates, considering that Latvia still belongs to low H. pylori resistance areas to clarithromycin, and therefore, clarithromycin-based triple therapy could be considered the first choice. The prevalence of the infection was considered $60 \%$, based on our previous studies [66].

Three different scenarios for a screen-and-treat strategy were evaluated: (1) eradication is limited every year just to persons reaching adulthood-18 years of age; for the estimates we considered a $100 \%$ adherence rate, since it was expected that the campaign would result in additional therapies outside the target group; (2) within a 3-year period, screen-and-treat would be offered to the risk-group defined as 40-64-year-old individuals; one third of the target group would be covered per year with the $70 \%$ compliance as an assumption; (3) within a 3-year period, screen-and-treat would be offered to all adult individuals assuming a similar $70 \%$ compliance rate. For scenarios 2 and 3, additional eradication of the group reaching adulthood was considered starting from year 2 . The results are given in Fig. 1.

Scenario 1 would lead to a moderate increase in clarithromycin and amoxicillin consumption, Scenario 2 to $\sim$ threefold increase, but Scenario 3 to more than a sixfold increase of clarithromycin, with a slightly lower (twofold) increase in amoxicillin consumption. Such an increase in antibiotic consumption would move Latvia from a group of countries with low antibiotic consumption to a group with average antibiotic consumption (see Fig. 2; data on antibiotic consumption

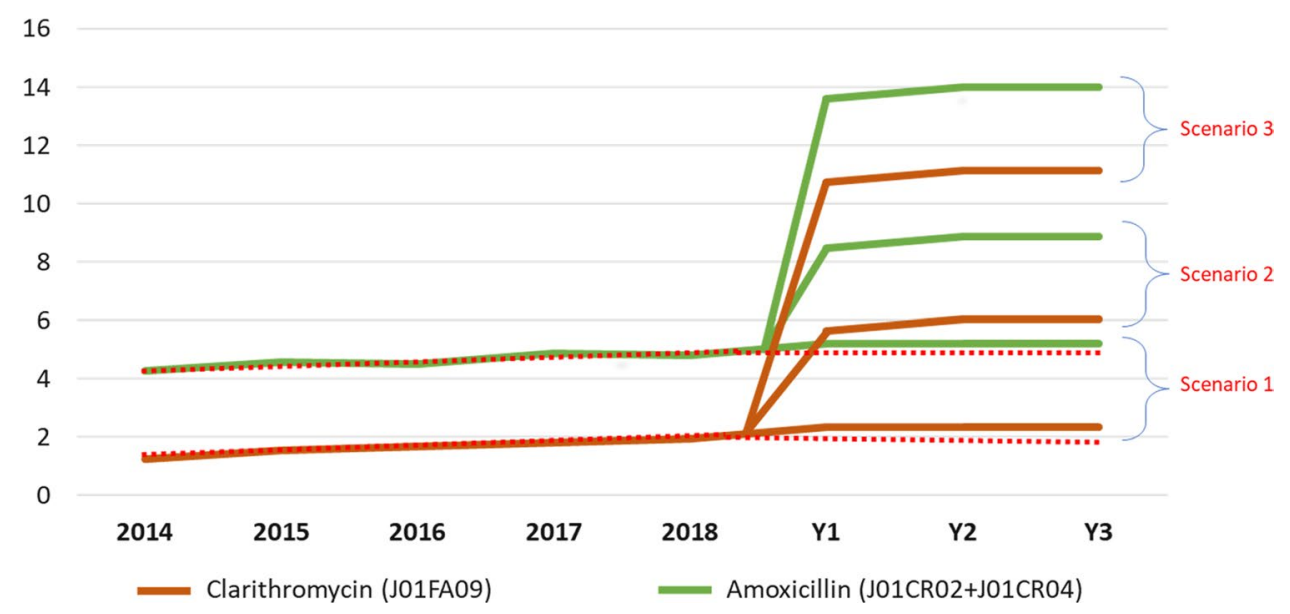

Fig. 1 Estimated antibiotic consumption in DDDs per 1000 inhabitants, with 3 different scenarios for search-and-treat strategy for $H$. pylori. Note: Scenario 1: eradication limited to anybody reaching 18 years of age. Scenario 2: the age group 40-64 years invited for screen-and-treat within a 3-year period, $70 \%$ compliance. Scenario 3: all adults invited for screen-and-treat within a 3-year period, $70 \%$ compliance. Vertical axis: DDDs per 1000 inhabitants per day. Horizontal axis: years. Dotted line: the trend-line without intervention 
Fig. 2 Potential overall consumption of antibacterials for systemic use (ATC group J01) in Latvia compared to other countries in the European Union/European Economic area, with the hypothetical scenarios of an H. pylori screenand-treat strategy expressed as DDD per 1000 inhabitants per day. Note: The bars in blue indicate the current consumption of antibacterials (including Latvia). The bars in red are consumption of antibacterials in Latvia with various scenarios during the first year of a screenand-treat strategy implementation. Scenario 1: eradication limited to anybody reaching 18 years of age. Scenario 2: the age group 40-64 years invited for screen-and-treat within a 3-year period; $70 \%$ compliance. Scenario 3: all adults invited for screen-and-treat within a 3-year period; $70 \%$ compliance

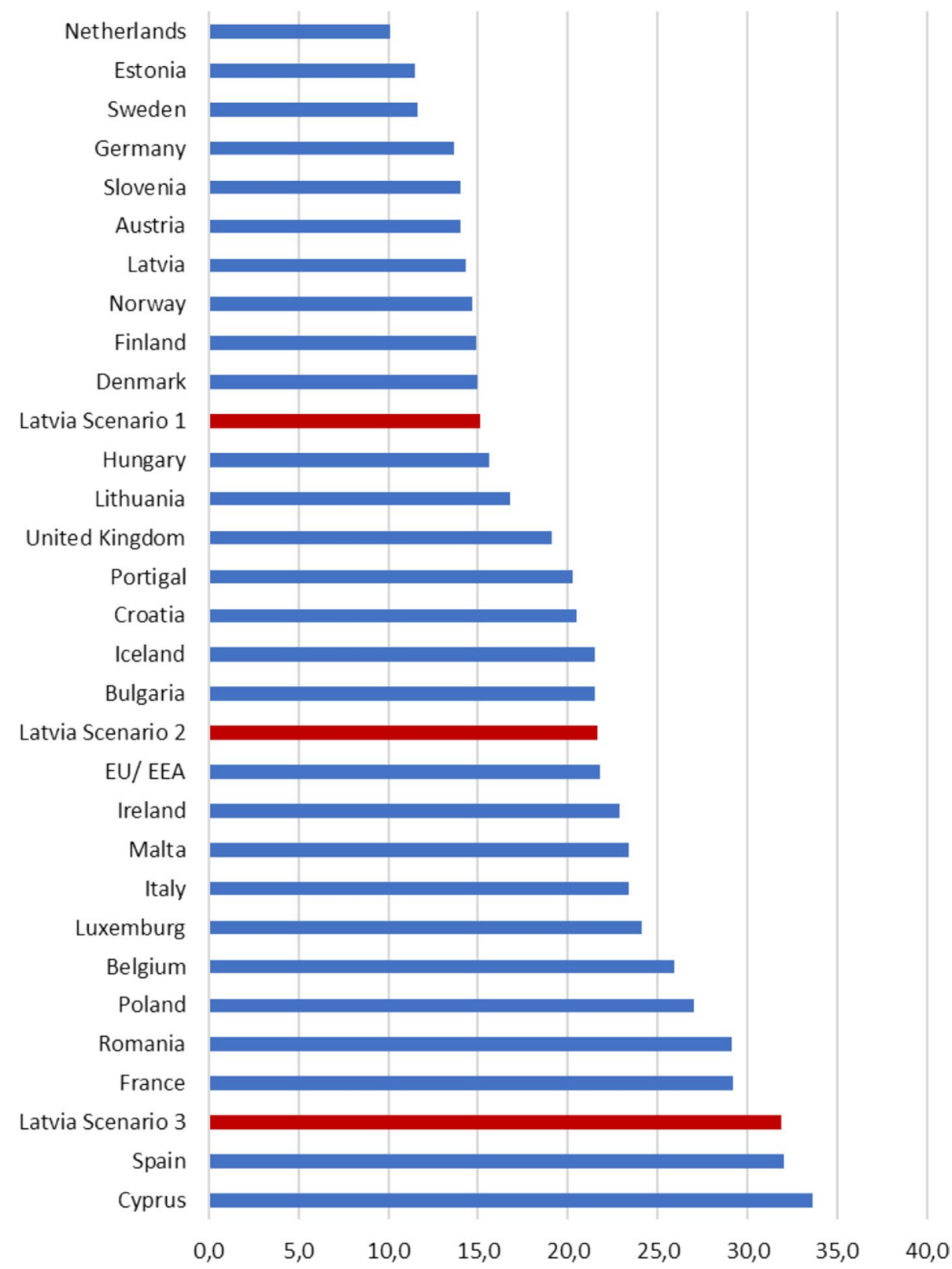

based on the Annual Epidemiological Report on Antimicrobial consumption for 2017, [58]).

\section{Potential Solutions}

Vaccine (either preventive or therapeutic) would be potentially the best solution of the problem $[10,11]$; however, current developments have not been promising. Non-antibiotic H. pylori eradication regimens have gained significant clinical interest. The use of natural products, including various plant (even mushroom) and fruit extracts, natural oils, Chinese herbs, garlic, ginger, green tea, curcumin, cranberries and pistacia gum have been studied, predominantly under laboratory conditions [67-70]. Some of these compounds had activity against $H$. pylori, but the results of clinical evaluations in monotherapies have been less promising; also, the quality of these trials has been criticized [67]. Probiotics as a single agent have been also used without major success [71].

Laboratory and animal experiments show the effectiveness of several non-antibiotic treatment modalities against $H$. pylori. Antimicrobial polypeptides ( $\mathrm{pH}$-sensitive, helix-coil conformation transitionable agent with a bactericidal activity) have been developed to target and selectively eradicate $H$. pylori as a single therapeutic agent, without significant effects on commensal bacteria [72]. Another group developed docosahexaenoic acid-loaded lipid nanoparticles with bactericidal activity against $H$. pylori [73]. This bactericidal 
agent could also eradicate $H$. pylori without affecting the other bacteria (Lactobacillus, E. coli, S. epidermidis and $S$. aureus) [74].

Since the abovementioned approaches are still far from clinical practice, regimens that are expected to interfere less with the microbiota and less likely to be responsible for gut (and other location) resistome development are more attractive for clinical applications in the near future.

Single antibiotic regimens, in particular those not containing macrolides, could attract interest in this respect. Use of high-dose amoxicillin is one case, although more frequent dosing is required due to the pharmacokinetics of this drug. High-dose amoxicillin-based dual therapy for first-line $H$. pylori eradication has so far been evaluated predominantly in Asia [75, 76], although a pilot study has been reported in Europe [77]. More profound reduction of the gastric acidity also could contribute to a higher effectiveness of the therapy. Sugimoto and Yamaoka [64] have recently reviewed the effectiveness of PCAB in $H$. pylori eradication therapies compared to the traditional PPI containing therapies, and demonstrated significant advantages of the PCAB. Therefore, one directions for future therapies could be PCAB and high-dose (multiple dose) amoxicillin in combination. Another approach would be the use of antimicrobial agents that are not typically used in managing life-threatening disease, as well as those causing less induction of the pool resistant genes.

Bismuth-based therapies are mainly used to overcome the resistance of $H$. pylori to commonly used antibiotics in clinical settings $[10,78,79]$. An additional gain with these therapies is avoiding the use of clarithromycin and amoxicillin. However, bismuth is not available in many countries. The concern with bismuth-related adverse events is predominantly related to the fact that in the 1970s, use of high-dose bismuth salts for long periods was associated with neurotoxicity; however, systemic review and meta-analysis on bismuth use for $H$. pylori eradication did not reveal serious adverse events for such therapy [80].

A recent meta-analysis by Ko et al. [81] has suggested the superiority of bismuth-containing therapies over nonbismuth regimens; furthermore, adding bismuth to conventional standard eradication regimens provides additional gain in the efficacy of the therapies. Another meta-analysis on a single capsule 10-day bismuth-containing quadruple therapy has suggested $\sim 90 \%$ eradication success both in first- and second-line therapy [82].

Short-term dysbiosis restoration to baseline levels within an 8-week period following 14-day bismuth quadruple therapy has been reported from Taiwan; 16S rRNA gene sequencing of the $\mathrm{V} 3-\mathrm{V} 4$ region and sampling before the treatment, as well as 2,8 , and 48 weeks thereafter, was used [83]. Therefore, bismuth-containing quadruple therapy is also related to dysbiosis; other antibacterial agents contained in this treatment, in particular metronidazole, could be responsible for perturbations in the microbiota. There are still insufficient data on the potency of bismuth-based therapies to induce and cause persistent resistome.

An alternative to the empiric eradication regimen is a $H$. pylori susceptibility-based individual therapy. This allows avoiding unnecessary use of antibiotics and increasing the effectiveness of the treatment [84]. However, this is considering only $H$. pylori resistance patterns, not the effects upon the other gut microbiome. Usually, even after H. pylori resistance testing, several options for eradication therapies are remaining, and lower negative effects upon the gut microbiome should ideally considered to be the choice.

Finally, narrowing the target group for $\mathrm{H}$. pylori eradication, e.g. by targeting young adults before family planning and, therefore, before the potential transmission of the infection to offspring, could be another approach in decreasing the misuse of antibiotics. In spite of the failures mentioned above, individual risk stratification based on gender, lifestyle factors, host and $H$. pylori genetics continue to be of interest in risk stratification.

\section{Cost-Effectiveness}

Several meta-analyses have suggested convincing cost-effectiveness of population-wide H. pylori eradication [85-87]. The benefit is likely to be highest in communities with a high risk of gastric cancer; in developed countries, such an approach could be either cost-effective or cost-neutral if considered on the positive side in reducing the cost of dyspepsia treatment [11].

Few other cost-effectiveness studies have since been published. In Denmark, a low H. pylori prevalence country, a 13-year follow-up of a randomized study population (20,011 individuals aged 40-65 years at enrollment) failed to achieve either quality-of-life or cost-effectiveness [88], whereas a modelling exercise in China proved cost-effective in a population-based screen-and-treat strategy related to gastric cancer, peptic ulcer disease and dyspepsia reduction. Furthermore, the highest effectiveness was in the age group of 20 years [89]. Screen-and-treat has also been estimated as cost-effective for employees in Japan [90]. However, these studies have not considered the potential costs associated to the increase in the pool of resistant bacteria.

The real costs behind the resistome are difficult to estimate; at least two major issues must be considered: 1) cost of the resistance and 2) cost-effectiveness of interventions to reduce it [91]. There is also a huge range in the estimates of additional cost, varying from $<\$ 5$ to $>\$ 55,000$ per patient episode [91]. However, generally the current costings could be an underestimated, and therefore, interventions in using 
antibiotics on a wide-scale could reflect as highly cost-saving benefit.

The hidden costs of antibiotic resistance in the United States have recently been estimated by Michaelidis et al. [92] who considered: (1) hospitalization costs; (2) secondline inpatient antibiotic costs; (3) second-line out-patient antibiotic costs, and (4) antibiotic stewardship costs. The authors estimated that the total hidden cost attributable to each ambulatory antibiotic prescription was $\$ 13$ (range: \$3-95), and each ambulatory antibiotic prescription would increase antibiotic costs by $65 \%$ (range: $15-475 \%$ ), if the cost of the resistance was incorporated into antibiotic costs paid by patients or payers [92]. Applying this estimate to the cost-effectiveness estimates of $H$. pylori eradication and modelling the costs of resistome for other countries globally probably would change the very beneficial cost-effectiveness picture of screen-and-treat strategy. The cost-effectiveness estimates should also incorporate those of organizing the activities and governance of the process, exactly as in traditional cancer screening program settings [93].

Finally, compliance rates of the target population, equal participation of both genders and coverage of the lower socioeconomic class members is critical for the success for any preventive strategy, and should be considered in cost-effectiveness modelling. Because of the necessity of antibiotic use and potential adverse events, participation rates could be lower for an $H$. pylori screen-and-treat strategy than for traditional screening approaches. This has been suggested by the participation results in the Danish community H. pylori screening trial [94] and is currently being addressed in the GISTAR cohort in Latvia [95].

\section{Conclusions}

The Screen-and-treat strategy clearly increases the consumption of antibiotics on a population level. In avoiding the problems of treating life-threatening diseases due to increased resistome, antibiotics with high potential for resistome induction, and use for treating life-threatening diseases (such as macrolides) should be avoided in populationbased $H$. pylori eradication regimens for otherwise healthy people. Narrowing of the target groups for the screen-andtreat strategy is desirable, e.g. for young people before family planning and potential transmission of $\mathrm{H}$. pylori to their offspring. Finally, in implementing any screen-and-treat strategy, this should be done under thorough surveillance corresponding to the general principles of screening governance, including surveillance of the incidence of serious infections and all-cause mortality.

Acknowledgments The work was supported by ERDF (European Regional Development Fund) in Latvia, Project id. nr. 1.1.1.1/18/A/184
'Optimisation of H. pylori eradication therapy for population-based gastric cancer prevention'.

\section{Compliance with Ethical Standards}

Conflict of interest The authors declare that they have no conflict of interest.

\section{References}

1. IARC Helicobacter pylori Working Group. Helicobacter pylori eradication as a strategy for preventing gastric cancer. Lyon: International Agency for Research on Cancer (IARC Working Group Reports, No. 8). 2014; https://publications.iarc.fr/BookAnd-Report-Series/Iarc-Working-Group-Reports/-Em-Helicobact er-Pylori-Em-Eradication-As-A-Strategy-For-Preventing-GastricCancer-2014. Accessed October 22, 2019.

2. Bray F, Ferlay J, Soerjomataram I, Siegel RL, Torre LA, Jemal A. Global cancer statistics 2018: GLOBOCAN estimates of incidence and mortality worldwide for 36 cancers in 185 countries. CA Cancer J Clin. 2018;68:394-424.

3. Forman D, Sierra MS. The current and projected global burden of gastric cancer. In: IARC Helicobacter pylori Working Group. Helicobacter pylori Eradication as a Strategy for Preventing Gastric Cancer. Lyon: International Agency for Research on Cancer (IARC Working Group Reports, No. 8); 2014: 5-15. https://publi cations.iarc.fr/Book-And-Report-Series/Iarc-Working-Group -Reports/-Em-Helicobacter-Pylori-Em-Eradication-As-A-Strat egy-For-Preventing-Gastric-Cancer-2014. Accessed October 22, 2019.

4. Plummer M, de Martel C, Vignat J, Ferlay J, Bray F, Franceschi S. Global burden of cancers attributable to infections in 2012: a synthetic analysis. Lancet Glob Health. 2016;4:e609-e616.

5. Plummer M, Franceschi S, Vignat J, Forman D, de Martel C. Global burden of gastric cancer attributable to Helicobacter pylori. Int J Cancer. 2015;136:487-490.

6. Kuipers EJ. Review article: exploring the link between Helicobacter pylori and gastric cancer. Aliment Pharmacol Ther. 1999;13:3-11.

7. De Vries AC, Kuipers EJ. Review article: Helicobacter pylori eradication for the prevention of gastric cancer. Aliment Pharmacol Ther. 2007;26:25-35.

8. Pimentel-Nunes P, Libanio D, Marcos-Pinto R, et al. Management of epithelial precancerous conditions and lesions in the stomach (MAPS II): European Society of Gastrointestinal Endoscopy (ESGE), European Helicobacter and Microbiota Study Group (EHMSG), European Society of Pathology (ESP), and Sociedade Portuguesa de Endoscopia Digestiva (SPED) guideline update 2019. Endoscopy. 2019;51:365-388.

9. Stubljar D, Jukic T, Ihan A. How far are we from vaccination against Helicobacter pylori infection? Expert Rev Vaccines. 2018;17:935-945.

10. Fallone CA, Moss SF, Malfertheiner P. Reconciliation of recent Helicobacter pylori treatment guidelines in a time of increasing resistance to antibiotics. Gastroenterology. 2019;157:44-53.

11. Malfertheiner P, Megraud F, O'Morain CA, et al. Management of Helicobacter pylori infection-the Maastricht V/Florence consensus report. Gut. 2017;66:6-30.

12. Lonnberg S, Sekerija M, Malila N, et al. Cancer screening: policy recommendations on governance, organization and evaluation of cancer screening. In: European Guide on Quality Improvement in Comprehensive Cancer Control. Belgium: National Institute of Public Health, Slovenia, Scientific Institute 
of Public Health; 2017:39-76. http://www.cancercontrol.eu/ guide-landing-page/. Accessed October 22, 2019.

13. Megraud F, Coenen S, Versporten A, et al. Helicobacter pylori resistance to antibiotics in Europe and its relationship to antibiotic consumption. Gut. 2013;62:34-42.

14. Brinkac L, Voorhies A, Gomez A, Nelson KE. The threat of antimicrobial resistance on the human microbiome. Microb Ecol. 2017;74:1001-1008.

15. Yap TW, Gan HM, Lee YP, et al. Helicobacter pylori eradication causes perturbation of the human gut microbiome in young adults. PloS One. 2016;11:e0151893.

16. Malhotra-Kumar S, Lammens C, Coenen S, Van Herck K, Goossens $\mathrm{H}$. Effect of azithromycin and clarithromycin therapy on pharyngeal carriage of macrolide-resistant streptococci in healthy volunteers: a randomised, double-blind, placebo-controlled study. Lancet. 2007;369:482-490.

17. Sugano K, Tack J, Kuipers EJ, et al. Kyoto global consensus report on Helicobacter pylori gastritis. Gut. 2015;64:1353-1367.

18. Coelho LGV, Marinho JR, Genta R, et al. IVth Brazilian consensus conference on Helicobacter pylori infection. Arq de Gastroenterol. 2018;55:97-121.

19. Mahachai V, Vilaichone RK, Pittayanon R, et al. Helicobacter pylori management in ASEAN: the Bangkok consensus report. J Gastroenterol Hepatol. 2018;33:37-56.

20. Fock KM, Katelaris P, Sugano K, et al. Second Asia-Pacific consensus guidelines for Helicobacter pylori infection. $J$ Gastroenterol Hepatol. 2009;24:1587-1600.

21. Chey WD, Leontiadis GI, Howden CW, Moss SF. ACG clinical guideline: treatment of Helicobacter pylori infection. Am J Gastroenterol. 2017;112:212-239.

22. Herrero R, Parsonnet J, Greenberg ER. Prevention of gastric cancer. JAMA. 2014;312:1197-1198.

23. Hiroi S, Sugano K, Tanaka S, Kawakami K. Impact of health insurance coverage for Helicobacter pylori gastritis on the trends in eradication therapy in Japan: retrospective observational study and simulation study based on real-world data. $B M J$ Open. 2017;7:e015855.

24. Choi KS, Jun JK, Suh M, et al. Effect of endoscopy screening on stage at gastric cancer diagnosis: results of the national cancer screening programme in Korea. $\mathrm{Br} J$ Cancer. 2015;112:608-612.

25. Kim SG, Jung HK, Lee HL, et al. Guidelines for the diagnosis and treatment of Helicobacter pylori infection in Korea, 2013 revised edition. J Gastroenterol Hepatol. 2014;29:1371-1386.

26. Tepeš B, Štabuc B. Slovenian society for gastroenterology and hepatology guidelines on the management of Helicobacter pylori infection. Zdrav Vestn. 2011;80:647-656.

27. Fallone CA, Chiba N, van Zanten SV, et al. The Toronto consensus for the treatment of Helicobacter pylori infection in adults. Gastroenterology. 2016;151:e14.

28. Malfertheiner P, Megraud F, O'Morain C, et al. Current concepts in the management of Helicobacter pylori infection: the Maastricht III consensus report. Gut. 2007;56:772-781.

29. Malfertheiner P, Megraud F, O'Morain CA, et al. Management of Helicobacter pylori infection-the Maastricht IV/Florence consensus report. Gut. 2012;61:646-664.

30. Wilson JM, Jungner YG. Principles and practice of mass screening for disease. Bol Oficina Sanit Panam. 1968;65:281-393.

31. Andermann A, Blancquaert I, Beauchamp S, Dery V. Revisiting Wilson and Jungner in the genomic age: a review of screening criteria over the past 40 years. Bull World Health Organ. 2008;86:317-319.

32. Zamani M, Ebrahimtabar F, Zamani V, et al. Systematic review with meta-analysis: the worldwide prevalence of Helicobacter pylori infection. Aliment Pharmacol Ther. 2018;47:868-876.
33. Weck MN, Brenner H. Prevalence of chronic atrophic gastritis in different parts of the world. Cancer Epidemiol Biomark Prev. 2006;15:1083-1094.

34. Ford AC, Delaney BC, Forman D, Moayyedi P. Eradication therapy in Helicobacter pylori positive peptic ulcer disease: systematic review and economic analysis. Am J Gastroenterol. 2004;99:1833-1855.

35. National Institute for Health and Care Excellence N. Clostridium difficile infection: risk with broad-spectrum antibiotics. 2015; nice.org.uk/guidance/esmpb1. Accessed April 02, 2017.

36. Owens RC Jr, Donskey CJ, Gaynes RP, Loo VG, Muto CA. Antimicrobial-associated risk factors for Clostridium difficile infection. Clin Infect Dis. 2008;46:S19-S31.

37. Trifan A, Girleanu I, Cojocariu C, et al. Pseudomembranous colitis associated with a triple therapy for Helicobacter pylori eradication. World J Gastroenterol. 2013;19:7476-7479.

38. Palleja A, Mikkelsen KH, Forslund SK, et al. Recovery of gut microbiota of healthy adults following antibiotic exposure. Nat Microbiol. 2018;3:1255-1265.

39. MacPherson CW, Mathieu O, Tremblay J, et al. Gut bacterial microbiota and its resistome rapidly recover to basal state levels after short-term amoxicillin-clavulanic acid treatment in healthy adults. Sci Rep. 2018;8:11192.

40. Wright GD. The antibiotic resistome: the nexus of chemical and genetic diversity nature reviews. Microbiology. 2007;5:175-186.

41. van Schaik W. The human gut resistome. Philos Trans $R$ Soc Lond B Biol Sci. 2015;370:20140087.

42. Forslund K, Sunagawa S, Kultima JR, et al. Country-specific antibiotic use practices impact the human gut resistome. Genome Res. 2013;23:1163-1169.

43. Jonsson M, Qvarnstrom Y, Engstrand L, Swedberg G. Clarithromycin treatment selects for persistent macrolide-resistant bacteria in throat commensal flora. Int J Antimicrob Agents. 2005;25:68-74.

44. Jakobsson H, Wreiber K, Fall K, Fjelstad B, Nyren O, Engstrand L. Macrolide resistance in the normal microbiota after Helicobacter pylori treatment. Scand J Infect Dis. 2007;39:757-763.

45. Sjolund M, Wreiber K, Andersson DI, Blaser MJ, Engstrand L. Long-term persistence of resistant Enterococcus species after antibiotics to eradicate Helicobacter pylori. Ann Intern Med. 2003;139:483-487.

46. Jakobsson HE, Jernberg C, Andersson AF, Sjolund-Karlsson M, Jansson JK, Engstrand L. Short-term antibiotic treatment has differing long-term impacts on the human throat and gut microbiome. PloS One. 2010;5:e9836.

47. Liou JM, Chen CC, Chang CM, et al. Long term changes of gut microbiota, antibiotic resistance, and metabolic parameters after Helicobacter pylori eradication a multicentre randomised trial. Lancet Infect Dis. 2019;19:1109-1120.

48. Bergman M, Huikko S, Huovinen P, Paakkari P, Seppala H, Finnish Study Group for Antimicrobial R. Macrolide and azithromycin use are linked to increased macrolide resistance in Streptococcus pneumoniae. Antimicrob Agents Chemother. 2006;50:3646-3650.

49. Monnet DL, MacKenzie FM, Lopez-Lozano JM, et al. Antimicrobial drug use and methicillin-resistant Staphylococcus aureus, Aberdeen, 1996-2000. Emerg Infect Dis. 2004;10:1432-1441.

50. Linder JA. Editorial commentary: antibiotics for treatment of acute respiratory tract infections: decreasing benefit, increasing risk, and the irrelevance of antimicrobial resistance. Clin Infect Dis. 2008;47:744-746.

51. Tamma PD, Cosgrove SE. Antimicrobial stewardship. Infect Dis Clin N Am. 2011;25:245-260.

52. Guardabassi L, Prescott JF. Antimicrobial stewardship in small animal veterinary practice: from theory to practice. Vet Clin $N$ Am Small Anim Pract. 2015;45:361-376. 
53. Minnesota Department of Health. One Health Antibiotic Stewardship Collaborative. https://www.health.state.mn.us/commu nities/onehealthabx/. Accessed August 31, 2019.

54. World Health Organization. 2nd Consultation of Member States and Partners on the Global Development and Stewardship Framework to Combat Antimicrobial Resistance. 2019; http:// www.who.int/phi/news/consultation_stewardship-framework/ en/. Accessed August 31, 2019.

55. Dyar OJ, Huttner B, Schouten J, Pulcini C, ESGAP. What is antimicrobial stewardship? Clin Microbiol Infect. 2017;23:793-798.

56. Swedres-Svarm. Swedres-Svarm Reports. 2014; http://www.sva. se/en/antibiotics/svarm-reports. Accessed May 26, 2015.

57. Molstad S, Lofmark S, Carlin K, et al. Lessons learnt during 20 years of the Swedish strategic programme against antibiotic resistance. Bull World Health Organ. 2017;95:764-773.

58. European Centre for Disease Prevention and Control. Antimicrobial consumption. In: ECDC. Annual Epidemiological Report for 2017. Stockholm: ESDC; 2018, 2019.

59. The White House. National action plan for combating antibiotic-resistant bacteria. 2015; https://www.whitehouse.gov/sites /default/files/docs/national_action_plan_for_combating_antib otic-resistant_bacteria.pdf. Accessed April 12, 2016.

60. Eccles S, Pincus C, Higgins B, Woodhead M, Guideline Development G. Diagnosis and management of community and hospital acquired pneumonia in adults: summary of NICE guidance. BMJ. 2014;349:g6722.

61. Wiersinga WJ, Bonten MJ, Boersma WG, et al. Management of community-acquired pneumonia in adults: 2016 guideline update from the Dutch Working Party on Antibiotic Policy (SWAB) and Dutch Association of Chest Physicians (NVALT). Neth J Med. 2018;76:4-13.

62. Spindler C, Stralin K, Eriksson L, et al. Swedish guidelines on the management of community-acquired pneumonia in immunocompetent adults-Swedish society of infectious diseases 2012 . Scand J Infect Dis. 2012;44:885-902.

63. Mandell LA, Wunderink RG, Anzueto A, et al. Infectious diseases society of America/American thoracic society consensus guidelines on the management of community-acquired pneumonia in adults. Clin Infect Dis. 2007;44:S27-S72.

64. O'Brien KS, Emerson P, Hooper PJ, et al. Antimicrobial resistance following mass azithromycin distribution for trachoma: a systematic review. Lancet Infect Dis. 2019;19:e14-e25.

65. Ferlay J, Ervik M, Lam F, et al. Global Cancer Observatory: Cancer Today. Lyon: International Agency for Research on Cancer. 2018; https://gco.iarc.fr/today. Accessed October 01, 2018.

66. Leja M, Cine E, Rudzite D, et al. Prevalence of Helicobacter pylori infection and atrophic gastritis in Latvia. Eur J Gastroenterol Hepatol. 2012;24:1410-1417.

67. Lin J, Huang WW. A systematic review of treating Helicobacter pylori infection with traditional Chinese medicine. World J Gastroenterol WJG. 2009;15:4715-4719.

68. Bonifacio BV, dos Santos Ramos MA, da Silva PB, Bauab TM. Antimicrobial activity of natural products against Helicobacter pylori: a review. Ann Clin Microbiol Antimicrob. 2014;13:54.

69. Zaidi SF, Muhammad JS, Usmanghani K, Sugiyama T. Review: pharmacological ins and outs of medicinal plants against Helicobacter pylori: a review. Pak J Pharm Sci. 2015;28:1171-1176.

70. Shmuely H, Domniz N, Yahav J. Non-pharmacological treatment of Helicobacter pylori. World J Gastrointest Pharmacol Ther. 2016;7:171-178

71. Losurdo G, Cubisino R, Barone M, et al. Probiotic monotherapy and Helicobacter pylori eradication: a systematic review with pooled-data analysis. World J Gastroenterol. 2018;24:139-149.

72. Xiong M, Bao Y, Xu X, et al. Selective killing of Helicobacter pylori with $\mathrm{pH}$-responsive helix-coil conformation transitionable antimicrobial polypeptides. Proc Natl Acad Sci U S A. 2017;114:12675-12680.

73. Seabra CL, Nunes C, Gomez-Lazaro M, et al. Docosahexaenoic acid loaded lipid nanoparticles with bactericidal activity against Helicobacter pylori. Int J Pharm. 2017;519:128-137.

74. Seabra CL, Nunes C, Bras M, et al. Lipid nanoparticles to counteract gastric infection without affecting gut microbiota. Eur J Pharm Biopharm. 2018;127:378-386.

75. Kwack W, Lim Y, Lim C, Graham DY. High dose ilaprazole/ amoxicillin as first-line regimen for Helicobacter pylori infection in Korea. Gastroenterol Res Pract. 2016;2016:1648047.

76. Park HY, Kang EJ, Kim DG, et al. High and frequent dose of dexlansoprazole and amoxicillin dual therapy for Helicobacter pylori infections: a single arm prospective study. Korean J Gastroenterol. 2017;70:176-180.

77. Zullo A, Ridola L, Francesco VD, et al. High-dose esomeprazole and amoxicillin dual therapy for first-line Helicobacter pylori eradication: a proof of concept study. Ann Gastroenterol. 2015;28:448-451.

78. Dore MP, Lu H, Graham DY. Role of bismuth in improving Helicobacter pylori eradication with triple therapy. Gut. 2016;65:870-878.

79. Graham DY, Dore MP, Lu H. Understanding treatment guidelines with bismuth and non-bismuth quadruple Helicobacter pylori eradication therapies. Expert Rev Anti Infect Ther. 2018;16:679-687.

80. Ford AC, Malfertheiner P, Giguere M, Santana J, Khan M, Moayyedi P. Adverse events with bismuth salts for Helicobacter pylori eradication: systematic review and meta-analysis. World J Gastroenterol WJG. 2008;14:7361-7370.

81. Ko SW, Kim YJ, Chung WC, Lee SJ. Bismuth supplements as the first-line regimen for Helicobacter pylori eradication therapy: systemic review and meta-analysis. Helicobacter. 2019;24:e12565.

82. Nyssen OP, McNicholl AG, Gisbert JP. Meta-analysis of threein-one single capsule bismuth-containing quadruple therapy for the eradication of Helicobacter pylori. Helicobacter. 2019;24:e12570.

83. Hsu PI, Pan CY, Kao JY, et al. Helicobacter pylori eradication with bismuth quadruple therapy leads to dysbiosis of gut microbiota with an increased relative abundance of Proteobacteria and decreased relative abundances of Bacteroidetes and Actinobacteria. Helicobacter. 2018;23:e12498.

84. Shiotani A, Lu H, Dore MP, Graham DY. Treating Helicobacter pylori effectively while minimizing misuse of antibiotics. Cleve Clin J Med. 2017;84:310-318.

85. Areia M, Carvalho R, Cadime AT, Rocha Goncalves F, DinisRibeiro M. Screening for gastric cancer and surveillance of premalignant lesions: a systematic review of cost-effectiveness studies. Helicobacter. 2013;18:325-337.

86. Lansdorp-Vogelaar I, Sharp L. Cost-effectiveness of screening and treating Helicobacter pylori for gastric cancer prevention. Best Pract Res Clin Gastroenterol. 2013;27:933-947.

87. Ford AC, Forman D, Hunt RH, Yuan Y, Moayyedi P. Helicobacter pylori eradication therapy to prevent gastric cancer in healthy asymptomatic infected individuals: systematic review and metaanalysis of randomised controlled trials. BMJ. 2014;348:g3174.

88. Hogh MB, Kronborg C, Hansen JM, Schaffalitzky de Muckadell OB. The cost effectiveness of Helicobacter pylori population screening-economic evaluation alongside a randomised controlled trial with 13-year follow-up. Aliment Pharmacol Ther. 2019;49:1013-1025.

89. Chen Q, Liang X, Long X, Yu L, Liu W, Lu H. Cost-effectiveness analysis of screen-and-treat strategy in asymptomatic Chinese for preventing Helicobacter pylori-associated diseases. Helicobacter. 2019;24:e12563. 
90. Kowada A. Cost-effectiveness of Helicobacter pylori screening followed by eradication treatment for employees in Japan. Epidemiol Infect. 2018;146:1834-1840.

91. Smith R, Coast J. The true cost of antimicrobial resistance. BMJ. 2013;346:f1493.

92. Michaelidis CI, Fine MJ, Lin CJ, et al. The hidden societal cost of antibiotic resistance per antibiotic prescribed in the United States: an exploratory analysis. BMC Infect Dis. 2016;16:655.

93. Lee YC, Chiang TH, Liou JM, Chen HH, Wu MS, Graham DY. Mass eradication of Helicobacter pylori to prevent gastric cancer: theoretical and practical considerations. Gut Liver. 2016;10:12-26.

94. Bomme M, Hansen JM, Wildner-Christensen M, Hallas J, Schaffalitzky de Muckadell OB. Effects of community screening for
Helicobacter pylori: 13-year follow-up evaluation of a randomized controlled trial. Clin Gastroenterol Hepatol. 2017;15:1715-1723.

95. Leja M, Park JY, Murillo R, et al. Multicentric randomised study of Helicobacter pylori eradication and pepsinogen testing for prevention of gastric cancer mortality: the GISTAR study. BMJ Open. 2017;7:e016999.

Publisher's Note Springer Nature remains neutral with regard to jurisdictional claims in published maps and institutional affiliations. 